\title{
COLETA DE AMOSTRAS E MONITORAMENTO DA ÁGUA DA ZONA NÃO SATURADA DO SUBSOLO
}

\author{
Carlos Tadeu C. do Nascimento e Sergio Koide \\ Universidade de Brasília, Departamento de Engenharia Civil, Campus Universitário, Asa Norte \\ 70910-900 Brasilia, DF - fone: (061) 348-2304 - fax (061) 347-4743 \\ skoide@guarany.unb.br
}

\section{RESUMO}

O objetivo deste trabalho é apresentar o procedimento para construção, instalação e utilização de lisímetros de sucção. Estes equipamentos destinam-se a obter amostras de água da porção não saturada do solo, podendo ser utilizados em estudos sobre contaminação da subsuperfície. Como exemplo de utilização dos lisímetros de sucção, apresenta-se o trabalho de monitoramento realizado no campus da Universidade de Brasília, em Brasília, DF. O local monitorado corresponde a uma área de infiltração de efluentes de fossa séptica. Os resultados obtidos possibilitaram avaliar o funcionamento dos lisímetros e acompanhar a propagação do efluente através do solo.

\section{INTRODUÇÃO}

Na Universidade de Brasília, Distrito Federal, uma pequena parte dos esgotos gerados é tratada com o uso de fossas sépticas. Uma dessas fossas, que serve ao alojamento dos estudantes, tem seus efluentes canalizados para um sistema de valas de infiltração. Durante o ano de 1997, o local das valas foi objeto de uma série de estudos sobre percolação e dispersão de efluentes no solo. Os trabalhos realizados nesse local incluíram a coleta e a análise de amostras de água da porção não saturada do subsolo.

As amostras de água foram obtidas por meio de lisímetros de sucção. De maneira geral, os lisímetros de sucção constituem-se de um tubo, provido de uma cápsula porosa na extremidade inferior. Uma sucção é aplicada no tubo e a água do subsolo migra através da cápsula porosa, se acumulando no interior do lisímetro. Os equipamentos utilizados foram construídos na Universidade de Brasília, com tubos e conexões de PVC, velas de filtro, registros para gás e válvulas de retenção para instalações hidráulicas prediais. O baixo custo dos componentes, a facilidade de construção, e os resultados satisfatórios obtidos mostraram que estes equipamentos podem substituir os modelos comerciais, importados, de difícil obtenção.

\section{ÁREA DE ESTUdO}

A área de estudo situa-se no campus da Universidade de Brasília. Os experimentos foram realizados próximo ao alojamento estudantil, no local de disposição dos efluentes gerados nos blocos residenciais (Figura 1 ). Os blocos $A$ e $B$, que compõem o alojamento, foram construídos em 1971. Cada bloco possui dois andares, com 23 apartamentos por andar. Cada apartamento comporta quatro moradores, totalizando 184 habitantes em cada bloco.

O sistema de tratamento e disposição dos esgotos domésticos compreende uma fossa séptica para cada bloco e um conjunto de valas de infiltração, construído em 1995, que atende somente ao bloco $B$. Os efluentes oriundos do bloco $A$ são dispostos diretamente sobre o solo. Os experimentos foram efetuados exclusivamente no local das valas de infiltração, distante 120 metros do bloco B e dentro do Centro Olímpico da Universidade.

O sistema de valas construído na Universidade de Brasília consiste de três estruturas quase paralelas, cada uma com 60 metros de comprimento e espaçadas cerca de 10 metros. Entre a fossa séptica e o conjunto de valas existe um gradeamento. O início, o ponto intermediário e o final de cada vala são identificados por poços de visita. Nos poços iniciais existem dispositivos que possibilitam ou impedem a passagem de efluente. Com esses mecanismos pode-se trabalhar com uma única vala de cada vez.

Durante o período de operação, cada vala recebe uma vazão média de 0,25 litros por segundo. Esse período habitualmente tem sido de duas semanas. Cada vala possui uma tubulação perfurada, de cerâmica, com 15 centímetros de diâmetro, envolvida por um leito de pedra britada. A profundidade de instalação das tubulações é variável, com aproximadamente 1 metro (Figura 2). 


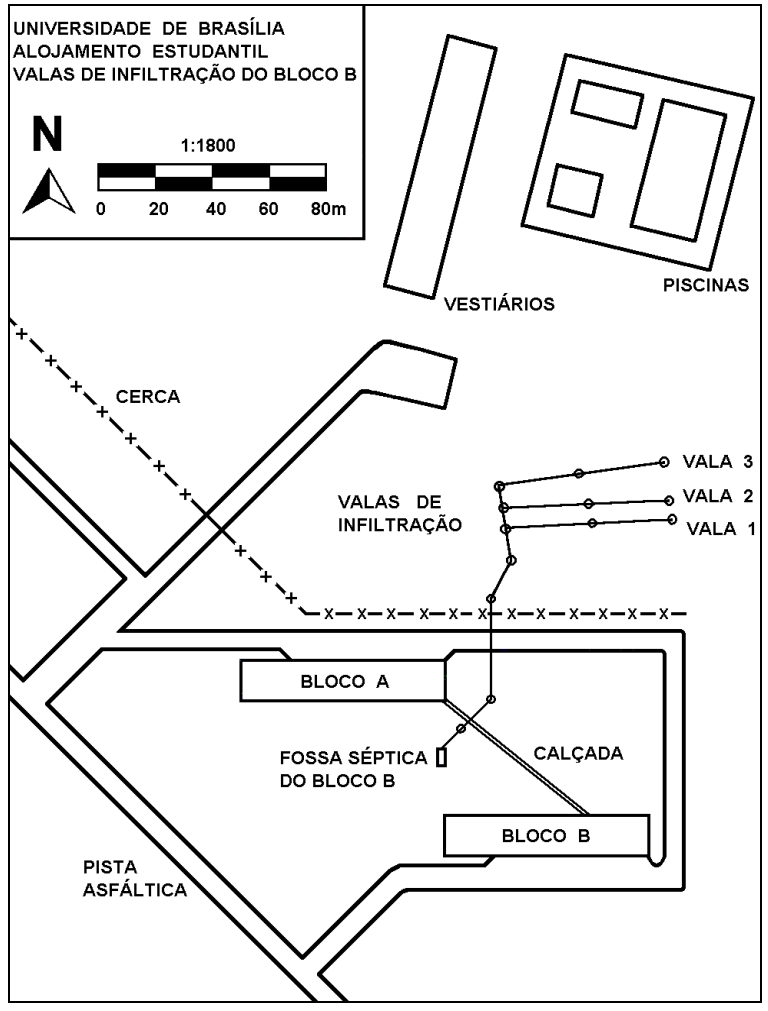

Figura 1. Planta da área de estudo.

Segundo levantamentos pedológicos realizados no Distrito Federal, o solo da área de estudo seria classificado como um latossolo (CODEPLAN, 1984; Haridasan, 1993). O latossolo do Distrito Federal caracteriza-se por uma cor vermelhoescura ou vermelho-amarelada, uma textura predominantemente argilosa e uma forte estrutura granular. A forte estruturação altera o comportamento que seria esperado para um solo argiloso. Desse modo, os latossolos do Distrito Federal costumam apresentar uma elevada capacidade de infiltração e muitas vezes pequena capacidade de adsorção.

Acredita-se que o processo de formação destes solos tenha sido fortemente condicionado pelo transporte de determinados elementos químicos pela água de percolação. Elementos como cálcio, magnésio e potássio teriam sido removidos, ao passo que teria ocorrido uma acumulação de ferro e alumínio (Haridasan, 1993).

Monteiro (1997) realizou estudos de caracterização dos solos da área de estudo. Segundo esse autor, o solo onde foram construídas as valas de infiltração apresenta uma granulometria predominantemente argilosa (88\%). A fração areia corresponderia a $9,5 \%$ e a fração silte corresponderia a 2,5\%. Mesmo assim, essa fração de areia indica-

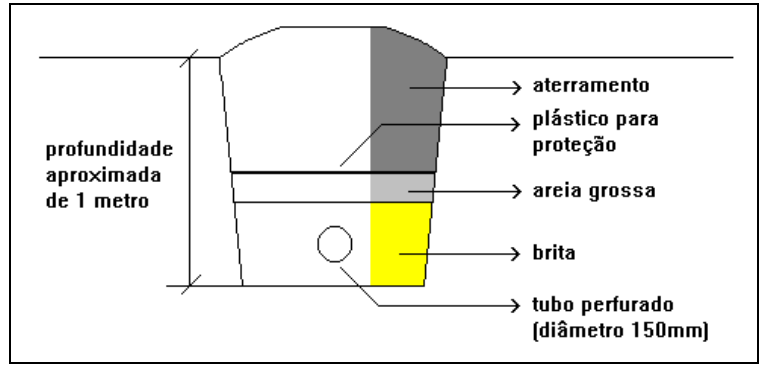

Figura 2. Perfil esquemático de uma vala de infiltração.

da pelos testes de granulometria, em geral é falseada pelo estado de agregação da argila, formando grânulos de difícil separação, conforme já observado em diversos estudos no DF (Santos, 1996). A porosidade deste solo é de aproximadamente $60 \%$ e a condutividade hidráulica, determinada com um permeâmetro do tipo Guelph, de $4.10^{-4} \mathrm{~cm} / \mathrm{s}$. O coeficiente de infiltração, determinado segundo a norma $n^{\circ} 7229$ da Associação Brasileira de Normas Técnicas (ABNT, 1993), é de $8.10^{-5} \mathrm{~cm} / \mathrm{s}$.

\section{LISÍMETROS DE SUCÇÃO}

Os lisímetros de sucção são equipamentos destinados a coletar amostras de água da zona não saturada. De maneira geral, constituem-se de um tubo, provido de uma cápsula porosa na extremidade inferior. Uma sucção é aplicada no tubo, e a água do subsolo migra através da cápsula porosa, acumulando-se no interior do lisímetro (ASTM, 1994).

Na zona não saturada, os poros do solo estão preenchidos por água e por ar. A água se distribui como um filme líquido sobre as partículas do solo formando uma superfície interconectada. Quando a cápsula porosa do lisímetro está saturada, forma-se um contato hidráulico entre o solo e o amostrador. É este contato hidráulico que possibilita a migração da água do solo para dentro do lisímetro.

Apenas o contato hidráulico não é suficiente para garantir o processo de amostragem. Também é necessário que se estabeleça um gradiente de pressão entre o solo e o lisímetro. Este gradiente é obtido aplicando-se uma sucção no interior do amostrador. Quando a sucção é maior que a força de atração entre o solo e a água ocorre a entrada de água no lisímetro. Note-se que a sucção aplicada deve ser grande o bastante para superar a sucção do solo, mas não tão grande que 
rompa o contato hidráulico entre a cápsula e o solo (ASTM, 1994).

A utilização de lisímetros na área de estudo teve por objetivo caracterizar o avanço do efluente disposto no solo através da vala de infiltração $n^{\circ} 3$. A escolha do local de instalação levou em conta a existência de trabalhos anteriores, realizados por Monteiro (1997), nesse conjunto de valas de infiltração. Esse autor construiu e instalou 13 lisímetros ao longo da vala $n^{\circ} 3$, em profundidades que variavam de 0,5 até 2,0 metros. As amostras coletadas foram analisadas quanto ao $\mathrm{pH}$, condutividade elétrica e nitrogênio amoniacal. Mantendo-se os lisímetros próximo à vala, existiria a possibilidade de se complementar o novo conjunto de dados com aqueles apresentados por Monteiro (1997).

Para este trabalho, 8 lisímetros foram construídos na Universidade de Brasília. Todas as peças, materiais e serviços necessários foram obtidos no mercado local. Estes lisímetros foram construídos segundo o esquema mostrado na Figura 3. A Tabela 1 apresenta as características de cada lisímetro.

Tabela 1. Características dos lisímetros construídos.

\begin{tabular}{ccc}
\hline Lisímetro & $\begin{array}{c}\text { Comprimento } \\
\text { total }\end{array}$ & $\begin{array}{c}\text { Profundidade } \\
\text { de instalação }\end{array}$ \\
\hline L1 & $2,0 \mathrm{~m}$ & $1,5 \mathrm{~m}$ \\
L2 & $2,0 \mathrm{~m}$ & $1,5 \mathrm{~m}$ \\
L3 & $2,5 \mathrm{~m}$ & $2,0 \mathrm{~m}$ \\
L4 & $2,5 \mathrm{~m}$ & $2,0 \mathrm{~m}$ \\
L5 & $3,0 \mathrm{~m}$ & $2,0 \mathrm{~m}$ \\
L6 & $3,0 \mathrm{~m}$ & $2,0 \mathrm{~m}$ \\
L7 & $3,0 \mathrm{~m}$ & $2,0 \mathrm{~m}$ \\
L8 & $3,0 \mathrm{~m}$ & $2,0 \mathrm{~m}$ \\
\hline
\end{tabular}

Os lisímetros construídos consistem de 3 partes distintas: 1) a extremidade inferior, na qual são instaladas uma válvula de retenção vertical e uma cápsula porosa fixadas a um cap de $60 \mathrm{~mm}$; 2) o corpo do lisímetro, que corresponde a um tubo de PVC soldável, com $60 \mathrm{~mm}$ de diâmetro; 3) a extremidade superior, formada por conexões de PVC soldável e um cap rosqueável, provido de um registro para gás.

A montagem da extremidade inferior envolveu compra, teste, limpeza e corte de velas de filtro para água; compra e usinagem de caps de PVC; e a montagem do conjunto cap + válvula + vela.

Dentre todas as marcas de velas para filtro disponíveis, optou-se por utilizar aquelas da marca Vênus, modelo V5, sem revestimento de sais de prata ou enchimento com carvão ativado. Esta

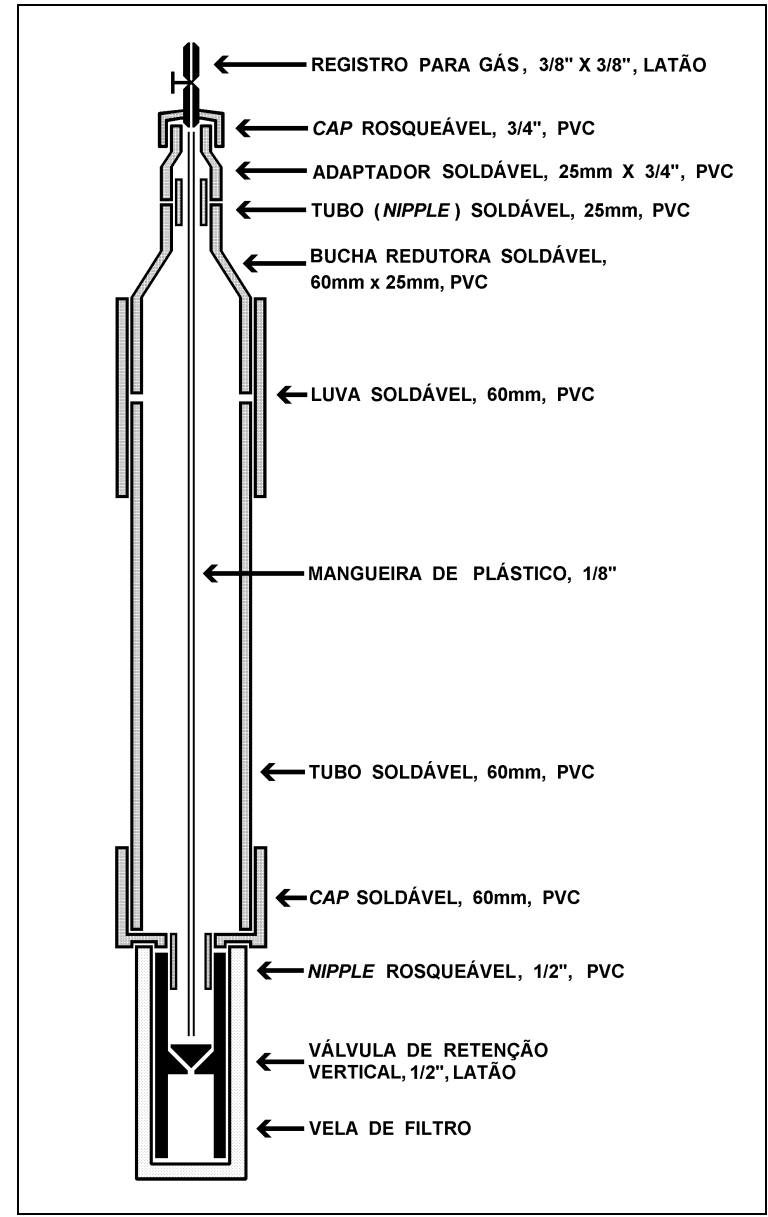

Figura 3. Desenho esquemático dos lisímetros construídos.

escolha baseou-se em testes previamente realizados por Monteiro (1997). Esses testes mostraram que o material poroso dessas velas, uma vez saturado, mantém a sucção por mais tempo que o material das velas de outras marcas. Observou-se que não existe uma uniformidade entre as velas de filtro, mesmo quando são da mesma marca. De 17 velas testadas somente 8 , com melhor desempenho nos testes, foram utilizadas.

O teste das velas consistiu em vedar a junção entre a cápsula porosa e a parte superior de plástico com adesivo de silicone, para evitar a entrada de ar e perda da sucção. Em seguida saturou-se o material poroso e, finalmente, aplicou-se uma sução de 60 centibares na vela. Cronometrouse o tempo em que o vácuo diminuia de 60 centibares até 20 centibares e escolheram-se aquelas velas onde o tempo foi maior. O valor de 20 centibares foi adotado como limite inferior por ser o valor médio do potencial matricial no local onde os 
lisímetros iriam ser instalados. A Tabela 2 mostra os resultados dos testes das velas selecionadas e o lisímetro onde cada uma foi colocada.

Tabela 2. Resultados dos testes com as velas selecionadas (cbar = centibares).

\begin{tabular}{ccc}
\hline $\mathrm{n}^{\circ}$ da vela & $\begin{array}{c}\text { Tempo de } \\
\text { sucção entre 60 } \\
\text { e 20 cbar }\end{array}$ & $\begin{array}{c}\text { Lisímetro onde } \\
\text { foi instalada }\end{array}$ \\
\hline 0 & $30 \min 50 \mathrm{~s}$ & $\mathrm{~L} 1$ \\
2 & $12 \min 40 \mathrm{~s}$ & $\mathrm{~L} 8$ \\
3 & $20 \min 00 \mathrm{~s}$ & $\mathrm{~L} 4$ \\
5 & $18 \min 00 \mathrm{~s}$ & $\mathrm{~L} 2$ \\
7 & $30 \min 45 \mathrm{~s}$ & $\mathrm{~L} 3$ \\
11 & $19 \min 00 \mathrm{~s}$ & $\mathrm{~L} 7$ \\
13 & $15 \min 45 \mathrm{~s}$ & $\mathrm{~L} 6$ \\
14 & $19 \min 20 \mathrm{~s}$ & $\mathrm{~L} 5$ \\
\hline
\end{tabular}

A limpeza das velas foi feita mergulhando cada uma delas em água destilada e forçando a passagem da água através da parede porosa. $\mathrm{Pe}$ riodicamente, media-se a condutividade elétrica da água que passava através da vela. A progressiva redução desse valor indicava a remoção de materiais solúveis presentes na vela e que poderiam interferir na qualidade das amostras que viriam a ser coletadas. Santos (1996) recomenda que a lavagem com água destilada seja precedida por uma limpeza com ácido clorídrico $(\mathrm{HCl})$ para meIhor remoção de óxidos de cálcio, sódio e ferro, usualmente presentes nas velas de filtro. Considerando que não seriam medidas as concentrações dessas substâncias, julgou-se desnecessária a lavagem com ácido clorídrico. A Tabela 3 ilustra o procedimento de limpeza. Após a limpeza, as velas foram serradas de modo a retirar a parte superior de plástico. A limpeza das velas destinou-se a minimizar uma contaminação derivada das próprias velas. No entanto, existe a possibilidade de ocorre- rem reações químicas entre as velas e o solo, e que tais reações possam interferir na qualidade das amostras.

Os caps de PVC, de $60 \mathrm{~mm}$, soldáveis, utilizados na extremidade inferior, foram modificados por meio de usinagem em torno mecânico. As modificações consistiram em abrir um orifício com rosca, com 1/2 polegada de diâmetro, no centro do cap, para fixar a válvula de retenção, e em fazer um sulco, no qual as velas cortadas pudessem ser encaixadas e coladas com cola epoxi (Figura 4). Todos os trabalhos de usinagem foram executados pelo Laboratório de Processos de Fabricação, da Universidade de Brasília.

As válvulas de retenção vertical foram utilizadas para garantir que a água amostrada, uma vez dentro do lisímetro, não retornasse ao solo, durante a progressiva redução da sucção. Utilizaram-se válvulas de latão, de $1 / 2$ polegada, da marca Mipel (Figura 4).

O corpo dos lisímetros é formado por um tubo de PVC, de $60 \mathrm{~mm}$, soldável, cortado de modo a atingir a profundidade a ser amostrada. Por dentro do lisímetro colocou-se uma mangueira de plástico com $1 / 8$ de polegada para retirar a água amostrada.

A montagem da extremidade superior envolveu a soldagem de uma luva, de uma bucha redutora e de um adaptador ao corpo do lisímetro, bem como a modificação de um cap rosqueável, de $3 / 4$ polegada. A modificação consistiu em fixar um registro para gás no centro do cap. Utilizou-se um registro de latão, da marca Jakwall, de $3 / 8$ polegada (Figura 4).

A instalação dos lisímetros foi feita utilizando-se um trado manual, tipo cavadeira, de 4 polegadas de diâmetro, com hastes de 85 centímetros. Uma vez aberto o furo, colocou-se uma mistura pastosa de água destilada com o solo do próprio local, peneirado, no seu interior. Somente após isto é que instalou-se o lisímetro. Esta mistura teve por

Tabela 3. Dados referentes à limpeza das velas (n.d. = não determinado; $\mu \mathbf{S} / \mathbf{c m}=$ microsiemens por centímetro).

\begin{tabular}{cccc}
\hline $\mathrm{n}^{\circ}$ da vela & condutividade inicial & condutividade final & volume de água gasto \\
\hline 0 & $29,2 \mu \mathrm{S} / \mathrm{cm}$ & $1,0 \mu \mathrm{S} / \mathrm{cm}$ & $\mathrm{n} . \mathrm{d}$. \\
2 & $13,8 \mu \mathrm{S} / \mathrm{cm}$ & $1,4 \mu \mathrm{S} / \mathrm{cm}$ & 2 litros \\
3 & $12,2 \mu \mathrm{S} / \mathrm{cm}$ & $1,5 \mu \mathrm{S} / \mathrm{cm}$ & 5 litros \\
5 & $10,3 \mu \mathrm{S} / \mathrm{cm}$ & $2,0 \mu \mathrm{S} / \mathrm{cm}$ & 5 litros \\
7 & $\mathrm{n} . \mathrm{d}$. & $1,0 \mu \mathrm{S} / \mathrm{cm}$ & $\mathrm{n} . \mathrm{d}$. \\
11 & $23,0 \mu \mathrm{S} / \mathrm{cm}$ & $1,3 \mu \mathrm{S} / \mathrm{cm}$ & 2 litros \\
13 & $17,2 \mu \mathrm{S} / \mathrm{cm}$ & $1,2 \mu \mathrm{S} / \mathrm{cm}$ & 2 litros \\
14 & $24,5 \mu \mathrm{S} / \mathrm{cm}$ & $1,4 \mu \mathrm{S} / \mathrm{cm}$ & 2 litros \\
\hline
\end{tabular}




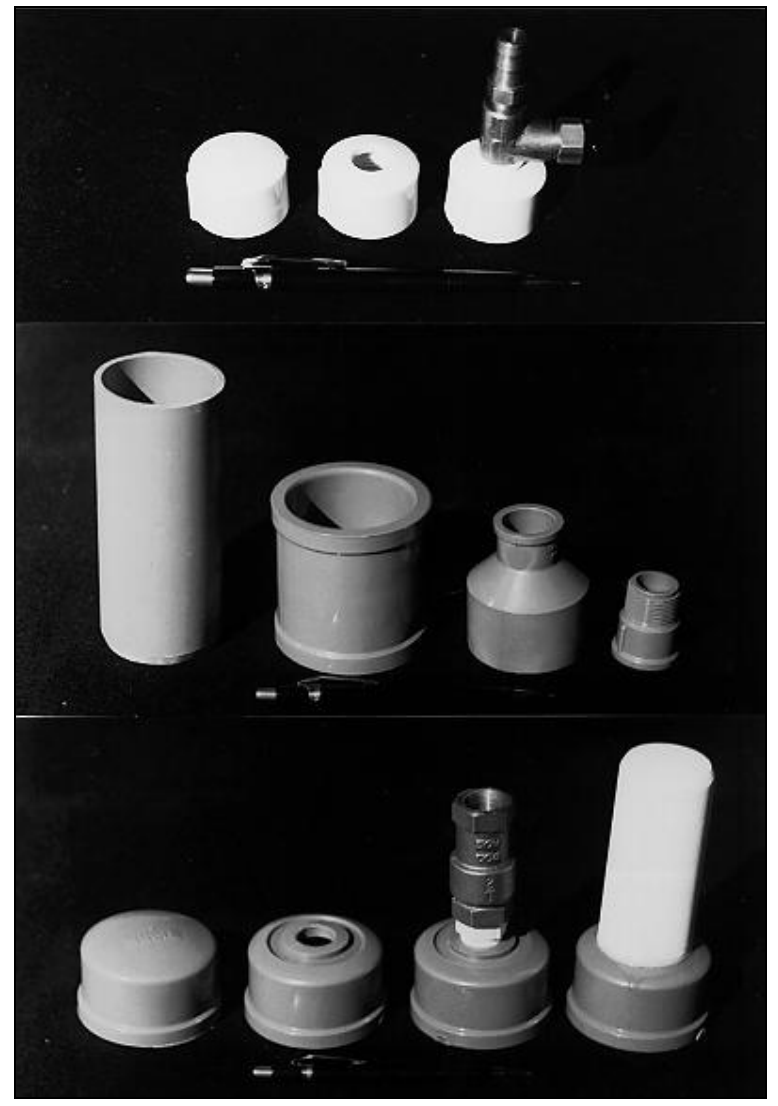

Figura 4. Componentes dos lisímetros: cap de $3 / 4$ de polegada com registro para gás; tubo, luva, bucha e adaptador de PVC soldável; cap de $\mathbf{6 0}$ milímetros, válvula de retenção e vela de filtro.

objetivo garantir o contato entre a cápsula porosa e as paredes do furo. O restante do espaço entre a parede do furo e o lisímetro foi preenchido com solo do próprio local, até a superfície do terreno (Figura 5).

Os lisímetros utilizados durante os trabaIhos de campo foram dispostos próximo à vala $\mathrm{n}^{\circ} 3$ (Figura 6). Utilizaram-se 8 lisímetros, 6 deles instalados na profundidade de $2 \mathrm{~m}$ e 2 instalados a $1,5 \mathrm{~m}$. Os lisímetros foram instalados no período de 03/09/1997 a 05/09/1997, e o primeiro conjunto de amostras foi coletado no dia 24/09/1997. Durante o período de coleta de dados com os lisímetros, a vala $n^{\circ} 3$ funcionou por 2 períodos: 18 até 25 de setembro e 2 até 13 de novembro.

A operação dos lisímetros pode ser resumida nos seguintes passos: 1) conectar uma bomba de vácuo manual ao registro para gás, na extremidade superior do lisímetro; 2) aplicar uma sucção de 60 centibares dentro do lisímetro; 3)

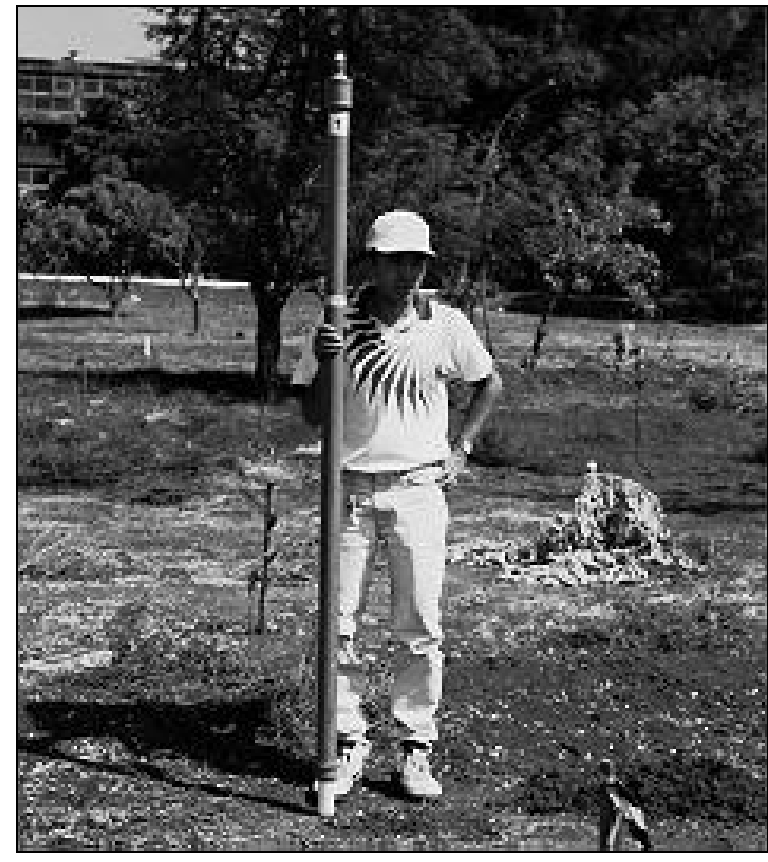

Figura 5. Procedimento para instalação dos lisímetros; data: 05/09/1997.

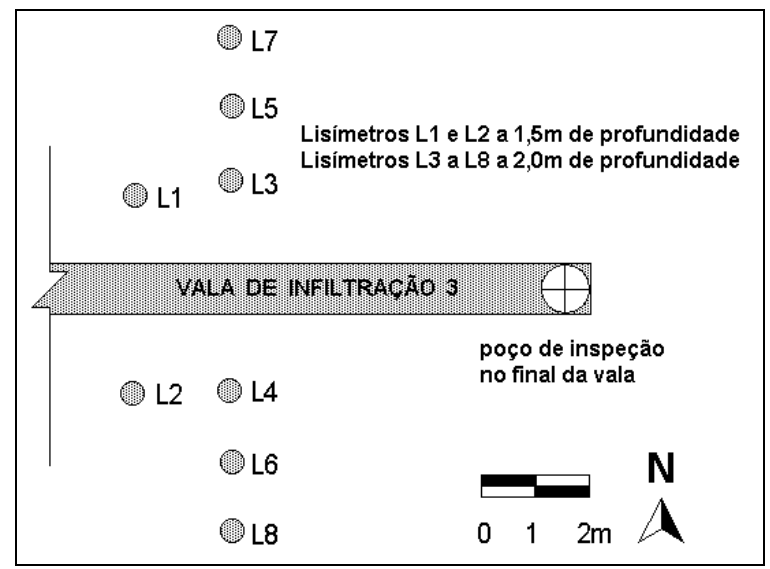

Figura 6. Desenho esquemático mostrando a localização dos lisímetros.

fechar o registro para gás e desconectar a bomba de vácuo; 4) aguardar durante algum tempo, até que a água do subsolo entre no lisímetro; 5) abrir o lisímetro, retirando o cap rosqueável; 6) coletar a água armazenada no interior do lisímetro, utilizando a bomba de vácuo manual e um kitassato (Figura 7 e Figura 8). Para acondicionar e transportar as amostras utilizaram-se frascos de vidro com capacidade de 0,5 litros.

Antes de se realizar a primeira coleta de amostras, acreditava-se que a operação dos lisí- 


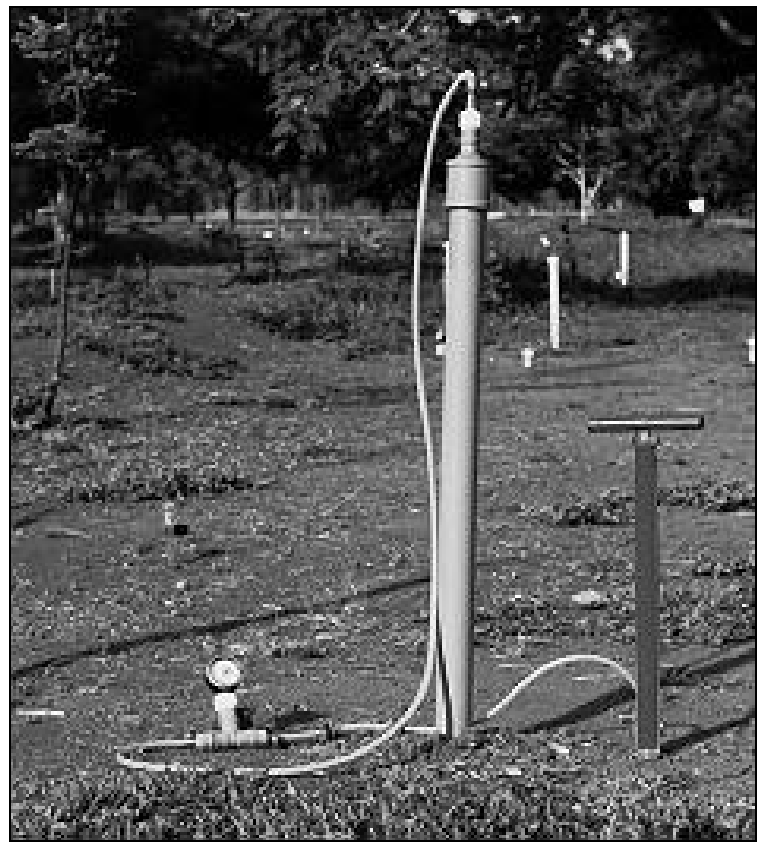

Figura 7. Operação do lisímetro L7: aplicação de sucção de 60 centibares, utilizando uma bomba de vácuo manual, provida de manômetro de vácuo; data: 24/10/1997.

metros seria direcionada pelos tempos apresentados na Tabela 2. Deste modo, no dia 24/09/1997, data da primeira coleta, o que se fez foi manter uma sucção de 60 cbar durante 1 hora, e, após isto, retirou-se as amostras. O volume total obtido foi de aproximadamente $20 \mathrm{ml}$, insuficiente para realizar todas as análises químicas planejadas. Decidiu-se então que era necessário aumentar o tempo de sucção, até o máximo possível. O primeiro passo seria determinar por quanto tempo os lisímetros materiam uma sucção satisfatória e, ao longo do período de coleta de amostras (24/09/1997 até 01/12/1997), verificou-se que a maioria dos lisímetros mantinha uma sucção maior que 20 centibares por até 72 horas. A exceção ficou por conta do lisímetro L2, no qual não se conseguiu coletar amostra alguma.

As amostras eram coletadas $1 \mathrm{vez}$ por semana. Após a retirada da água contida no interior dos 8 amostradores, aplicava-se uma sucção de 60 centibares e fechava-se cada um deles. No período entre duas coletas sucessivas, fazia-se uma manutenção diária dessa sucção. O objetivo dessa manutenção era manter os lisímetros constantemente com uma sucção próxima de 60 centibares e com isto garantir um volume representativo de amostras de água. Sem esta manutenção, em aproximadamente 72 horas a sucção aplicada em

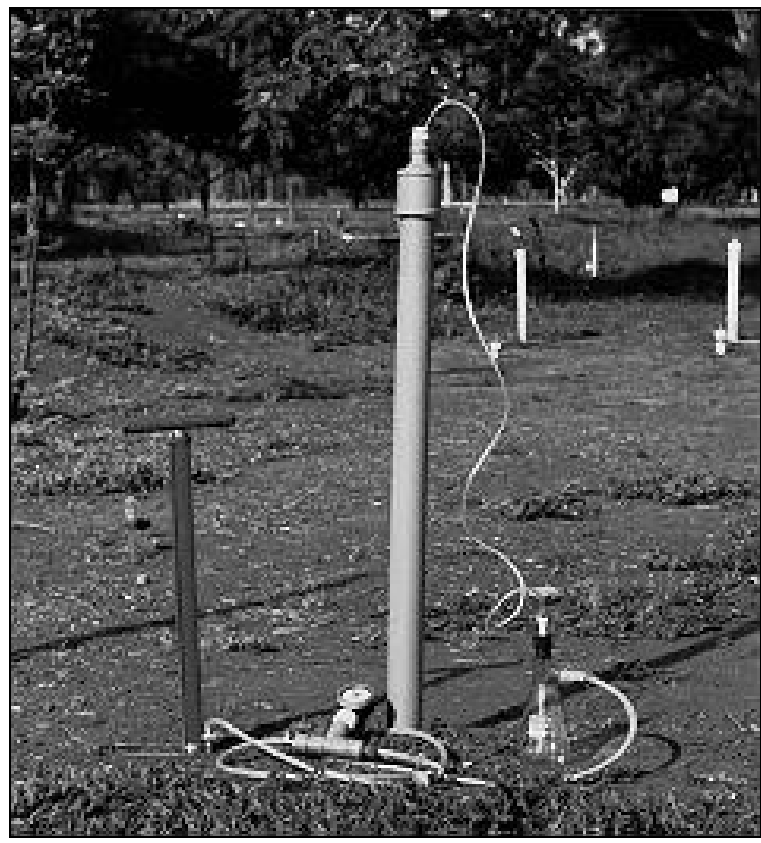

Figura 8. Operação do lisímetro L7: coleta de amostra, utilizando uma bomba de vácuo manual e um kitassato; data: 24/10/1997.

cada lisímetro já teria diminuído até valores próximos aos do solo, ou seja 20 centibares, e neste caso não haveria mais a migração da água para dentro do amostrador.

A manutenção da sucção por um tempo relativamente grande, permitiu obter volumes representativos de amostra, mas tornou difícil o estabelecimento de uma relação temporal entre a emissão do efluente e a sua coleta pelo lisímetro.

\section{RESULTADOS OBTIDOS}

O período de coleta de amostras foi de 24/09/1997 até 01/12/1997, o que correspondeu a 9 campanhas de amostragem. A vala de infiltração, por sua vez, funcionou de 18 a 25 de setembro e de 2 a 13 de novembro. Os maiores volumes de amostra foram obtidos nos dias 17/10/1997, 23/11/1997, 04/10/1997 e 01/12/1997. O lisímetro L1 destacou-se pelos volumes relativamente grandes de amostra fornecidos, chegando, por duas vezes, a armazenar cerca de 4 litros de líquido no seu interior (Tabela 4).

Ao final das 9 campanhas de amostragem o lisímetro L1 retirou cerca de 17 litros de água do subsolo. O lisímetro $\mathrm{L} 8$, o $2^{\circ}$ colocado em termos de volume fornecido, retirou cerca de 6 litros. 0 fato do lisímetro $L 1$ ter apresentado um rendimento 
Tabela 4. Volume de água contido nos lisímetros (litros).

\begin{tabular}{clllllllll}
\hline campanha & L1 & L2 & L3 & L4 & L5 & L6 & L7 & L8 & $\Sigma$ \\
\hline $1^{\mathrm{a}}-24 / 09 / 97$ & 0 & 0 & 0,002 & 0 & 0 & 0,007 & 0 & 0,013 & 0,022 \\
$2^{\mathrm{a}}-04 / 10 / 97$ & 3 & 0 & 1 & 0,4 & 0 & 1,5 & 0 & 0,025 & 5,925 \\
$3^{\mathrm{a}}-10 / 10 / 97$ & 0,065 & 0 & 0,35 & 0,083 & 0,17 & 1 & 0,115 & 0,75 & 2,533 \\
$4^{\mathrm{a}}-17 / 10 / 97$ & 4 & 0 & 0,5 & 0,2 & 0,3 & 1 & 0,15 & 1 & 7,15 \\
$5^{\mathrm{a}}-24 / 10 / 97$ & 1,5 & 0 & 0,35 & 0,02 & 0,35 & 0,85 & 0,25 & 0,85 & 4,17 \\
$6^{\mathrm{a}}-30 / 10 / 97$ & 0,8 & 0 & 0,2 & 0,02 & 0,25 & 0,475 & 0,1 & 0,475 & 2,32 \\
$7^{\mathrm{a}}-06 / 11 / 97$ & 1,2 & 0 & 0,18 & 0,055 & 0,055 & 0,09 & 0,024 & 0,1 & 1,704 \\
$8^{\mathrm{a}}-23 / 11 / 97$ & 4 & 0 & 1 & 0 & 0,04 & 0 & 0,215 & 1,6 & 6,855 \\
$9^{\mathrm{a}}-01 / 12 / 97$ & 2,5 & 0 & 0,5 & 0,12 & 0,3 & 0,7 & 0,3 & 1,4 & 5,82 \\
$\Sigma$ & 17,065 & 0 & 4,082 & 0,898 & 1,465 & 5,622 & 1,154 & 6,213 & \\
\hline
\end{tabular}

diferenciado deve-se, possivelmente ao fato de estar próximo à vala e na profundidade de 1,5 metros. Todos os outros lisímetros estavam a diferentes distâncias da vala e na profundidade de 2 metros. O lisímetro L2 nunca chegou a funcionar, e supõem-se que a vela tenha sido avariada durante o processo de instalação.

A distância à vala pareceu condicionar o volume de amostra obtido apenas no caso dos lisímetros L1, L3, L5 e L7. Nesses lisímetros, verificou-se que quanto mais perto da vala, maior o volume da amostra. Para os lisímetros L4, L6 e L8, no entanto, observou-se uma tendência contrária.

Cada lisímetro tende, naturalmente, a apresentar um comportamento particular, devido às diferenças entre as velas de filtro instaladas em cada um deles. Velas menos permeáveis, por exemplo, deveriam deixar passar menos água, e apenas durante os períodos de maior fluxo de efluente no solo. Contudo, deve ser lembrado que a sucção foi mantida com igual intensidade em todos os lisímetros. Além disso, as amostras coletadas não devem sofrer uma influência significativa da porosidade das velas, uma vez que as quantidades amostradas são pequenas em relação ao fluxo total que está ocorrendo no solo.

As campanhas de amostragem de número 1 e 7, foram realizadas durante os períodos de operação da vala $n^{\circ} 3$. Essas duas campanhas foram aquelas que forneceram os menores volumes de amostra. Deste modo, exceto talvez para o lisímetro $L 1$, o fato da vala estar funcionando ou não tem, a curto prazo, pouca influência nos volumes amostrados. Acredita-se que somente cerca de 1 semana após o final da operação da vala, o efluente atinge os lisímetros posicionados a 2 metros de profundidade. Isto explicaria os volumes relativamente grandes obtidos nas campanhas de número 2 e 8 . O resultado das campanhas 3 e 9 mostraram a continuidade dessa tendência.
As campanhas de número 5 e 6 ocorreram quando a vala $n^{\circ} 3$ já havia deixado de operar a vários dias; o subsolo já deveria estar relativamente seco e disto decorreriam os baixos volumes coletados. A campanha de amostragem $n^{\circ} 4$ foi aquela em que, somando-se os volumes contidos em cada lisímetro, obteve-se cerca de 7 litros de líquido, o maior valor dentre todas as campanhas. Ocorre que desses 7 litros, 4 foram obtidos exclusivamente do lisímetro $L 1$, ao passo que os volumes obtidos nos demais lisímetros foram praticamente os mesmos encontrados durante a $3^{a}$ campanha de amostragem. Acredita-se que o resultado da campanha $n^{\circ} 4$ reflita a passagem do final da frente de umidade, originária da vala, pelos lisímetros a 2 metros de profundidade.

Todas as amostras coletadas foram analisadas no Laboratório de Análise de Água da Universidade de Brasília. Os parâmetros determinados foram a condutividade elétrica, o $\mathrm{pH}$, e as concentrações de cloreto e de nitrato (Tabela 5).

Com relação às análises químicas, verificou-se que os resultados obtidos em cada lisímetro não variavam significativamente entre cada campanha de amostragem. Assim, para efeito de análise de dados, optou-se por apresentar os valores médios de cada parâmetro, ao longo de todo o período de amostragem.

$\mathrm{Na}$ Figura 9, pode ser observado um perfil assimétrico na seção transversal à vala número 3 . As amostras obtidas no lado esquerdo da vala mostram uma progressiva diminuição das concentrações de cloreto, de nitrato e da condutividade elétrica. No lado direito ocorre um decréscimo abrupto, seguido por uma elevação dos valores desses parâmetros. Os gráficos indicam portanto, que existe uma região de pouca influência do efluente no local do lisímetro L5. A existência dessa região deve-se à uma deformidade do bulbo de umidade sob a vala 3. Outras informações, obtidas 
Tabela 5. Análises químicas em amostras de água da zona não saturada, e de efluente; valores médios $(\mu \mathbf{S} / \mathbf{c m}=$ microsiemens por centímetro; $\mathbf{m g} / \mathbf{l}=$ miligramas por litro).

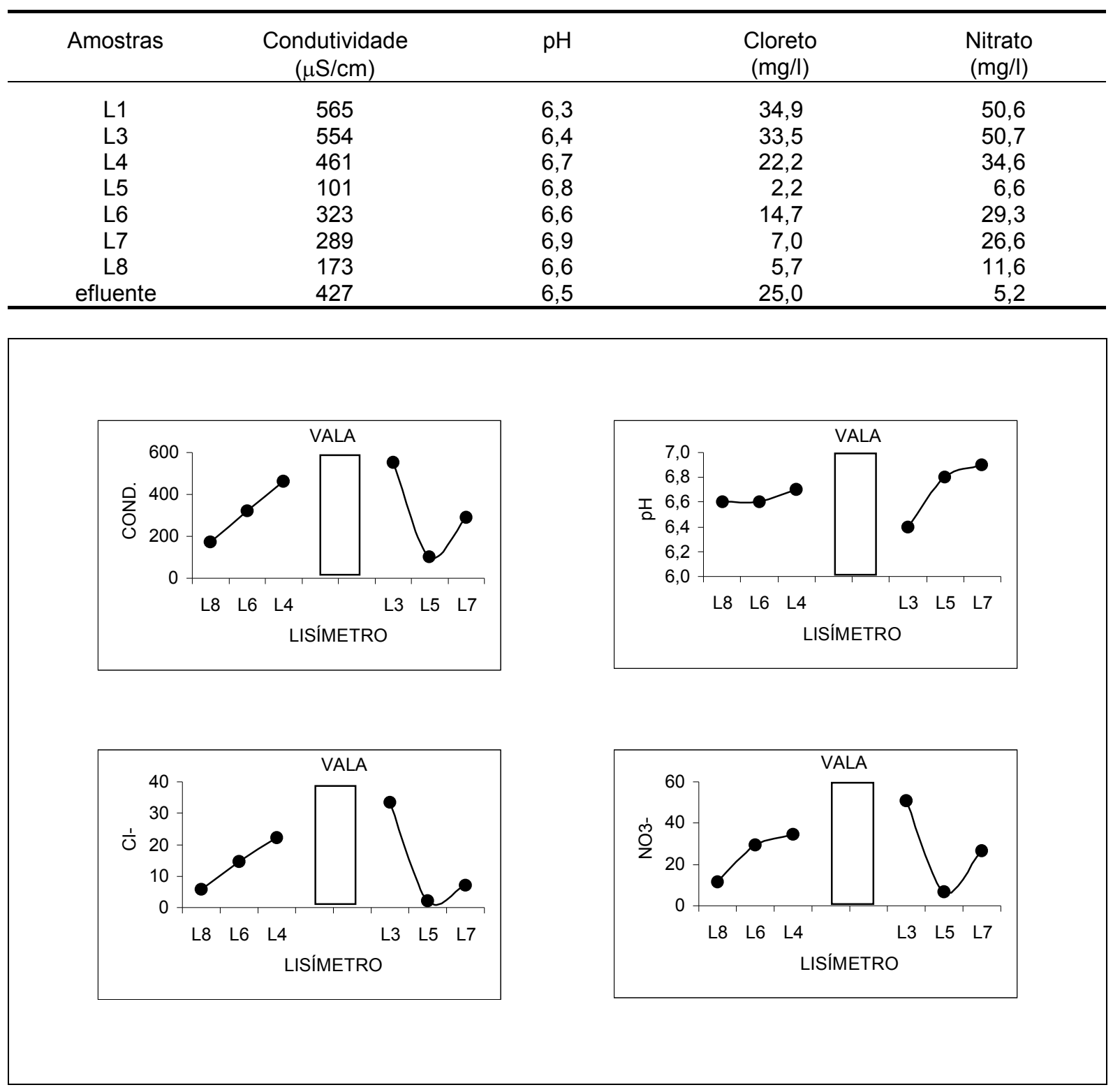

Figura 9. Gráficos com os resultados das análises químicas em amostras de água da zona nãosaturada: condutividade $(\mu \mathrm{S} / \mathrm{cm}), \mathbf{p H}$, cloreto $(\mathrm{mg} / \mathrm{l})$ e nitrato $(\mathrm{mg} / \mathrm{l})$.

por meio de tensiômetros e de métodos geofísicos, mostraram que o bulbo de umidade que se desenvolve sob a vala de infiltração número 3 tem um formato assimétrico (Nascimento, 1998). No trecho final da vala, primeiro ocorre um espalhamento lateral e depois o umedecimento do solo em direção à superfície. O mecanismo causador deste fenômeno aparentemente está vinculado a uma elevada declividade da tubulação de infiltração. A tubulação muito inclinada favorece o acúmulo de efluente no trecho final da vala, inclusive dentro do poço de inspeção. Quanto maior o volume de efluente acumulado, maior a carga hidráulica no trecho final da vala número 3 . Este aumento da carga seria o responsável pelo movimento ascendente do efluente no subsolo. $\mathrm{O}$ gráfico referente ao $\mathrm{pH}$ indica que ocorre um aumento dos valores com o progressivo distanciamento da vala. 


\section{CONCLUSÕES}

Os resultados apresentados mostram que os lisímetros construídos na Universidade de Brasília funcionaram de maneira satisfatória. Os volumes de água amostrados através desses equipamentos foram diretamente proporcionais à quantidade de umidade existente no solo. No entanto, a capacidade de manter a sucção por alguns dias possibilitou a obtenção de amostras mesmo nos períodos de baixa umidade.

A capacidade de manter a sucção dependeu da qualidade das velas utilizadas e dos cuidados tomados durante a montagem das várias partes do equipamento, principalmente daquelas que não são coladas. Além disso, o modo segundo o qual os lisímetros foram instalados e o método adotado para operá-los também influenciaram fortemente os resultados obtidos.

A qualidade desses resultados pode ser avaliada tanto em termos de volume de amostra fornecido, como em relação às características dessas amostras. O procedimento para limpeza das velas e dos demais componentes deve ser coerente com os parâmetros que se espera analisar nas amostras de água. Em função da constituição das velas, é esperado que ocorra certa dissolução de óxidos, principalmente em condições ácidas. Assim, caso o objetivo da amostragem seja a detecção de metais, recomenda-se uma pré-lavagem com ácido, conforme recomendado por Wood (1973)

No caso das valas de infiltração da Universidade de Brasília, as informações obtidas através das amostras coletadas com os lisímetros complementaram um estudo mais amplo que incluiu a utilização de tensiômetros, de poços de monitoramento e de técnicas geofísicas (Nascimento, 1998). Este estudo demonstrou que a contaminação advinda da infiltração do efluente de fossa séptica já atingiu um aqüífero freático que existe sob as valas a cerca de oito metros de profundidade.

\section{REFERÊNCIAS}

ABNT. NBR 7229 (1993). Projeto, construção e operação de sistemas de tanques sépticos. Associação Brasileira de Normas Técnicas, Rio de Janeiro.

ASTM. ASTM D 4696-92 (1994). Standard guide for pore-liquid sampling from the vadose zone. In: ASTM Standards on ground water and vadose zone investigations. 2. ed. American
Society for Testing and Materials, Philadelphia, p220-250.

CODEPLAN (1984). Atlas do Distrito Federal. Companhia do Desenvolvimento do Planalto Central, Brasília.

HARIDASAN, M. (1993). Solos do Distrito Federal. In: PINTO, M. N. Cerrado; caracterização, ocupação e perspectivas, 2.ed. Universidade de Brasília, Brasília, p321-344.

MONTEIRO, M. P. (1997). Estudos de percolação e dispersão de efluentes de fossas sépticas no solo; dissertação de mestrado. Universidade de Brasília, Departamento de Engenharia Civil, Brasília.

NASCIMENTO, C. T. C. (1998). Comparação de dados de levantamentos geofísicos e de campanhas de amostragem em estudos de contaminação do subsolo; dissertação de mestrado. Universidade de Brasília, Departamento de Engenharia Civil, Brasília.

SANTOS, P. C. V. (1996). Estudos da contaminação de água subterrânea por percolado de aterro de resíduos sólidos - caso Jockey Club - DF; dissertação de mestrado. Universidade de Brasília, Departamento de Engenharia Civil, Brasília.

WOOD, W. W. (1973). A technique using porous cups for water sampling at any depth in the unsaturated zone. Water Resources Research, 9 (2):486-488.

\section{Collection of Water Samples from the Vadose Zone of Soil}

\section{ABSTRACT}

The purpose of this work is to present the procedure for construction, instalation and utilization of suction lysimeters. These equipments are intended to collect water samples from the vadose zone, and can be used in ground contamination studies. An example of suction lysimeter utilization is the monitoring work carried out at the campus of the University of Brasilia, in Brasilia. The monitored site is a septic tank effluent infiltration area. The results obtained made possible to evaluate lysimeter performance and observe effluent migration through the soil. 